\title{
REVIEW
}

\section{Pathobiology of pulmonary arterial hypertension and right ventricular failure}

\author{
Norbert F. Voelkel*, Jose Gomez-Arroyo*, Antonio Abbate*, \\ Harm J. Bogaard" and Mark R. Nicolls ${ }^{\star}$
}

\begin{abstract}
Pulmonary arterial hypertension (PAH) is no longer an orphan disease. There are three different classes of drugs for the treatment of PAH that are currently being used and an increasing number of patients are being treated with a single drug or combination therapy. During the last $25 \mathrm{yrs}$, new insights into the pathobiology of PAH have been gained. The classical mechanical concepts of pressure, flow, shear stress, right ventricle wall stress and impedance have been complemented with the new concepts of cell injury and repair and interactions of complex multicellular systems. Integrating these concepts will become critical as we design new medical therapies in order to change the prognosis of patients with these fatal diseases. This review intends to summarise recent pathobiological concepts of PAH and right ventricle failure mainly derived from human studies, which reflect the progress made in the understanding of this complex group of pulmonary vascular diseases.
\end{abstract}

\section{KEYWORDS: Bone morphogenic type II receptor, genetics, growth factors, inflammation}

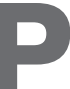

ulmonary hypertension $(\mathrm{PH})$, like systemic hypertension, is not a single disease but a group of diseases that share the defining element of a mean pulmonary arterial pressure $(P$ pa $) \geqslant 25 \mathrm{mmHg}$. $\mathrm{PH}$ has been classified and divided into five groups [1]. The World Health Organization Group 1, or pulmonary arterial hypertension (PAH), includes diseases characterised by elevated $P$ pa and elevated blood flow resistance due to a pre-capillary pulmonary microangiopathy. Whereas 25 yrs earlier idiopathic $\mathrm{PAH}$ (IPAH) was a disease of young females, data from the Registry to Evaluate Early and Long Term PAH Disease Management (REVEAL) now indicate that, at least in the USA, the phenotype of PAH has significantly changed. Today, up to $79 \%$ of patients are females close to menopausal age, with a higher predominance of females (3.6 to 1 female to male ratio) and a large percentage of obesity [2]. However, there is an apparent discrepancy in the PAH phenotype between US and European registries [3-5], perhaps suggesting the presence of currently unidentified environmental factors that could contribute to the development and progression of the disease.

PAH is no longer an orphan disease [6]. In the last $15 \mathrm{yrs}$, three classes of drugs have been developed and an increasing number of patients are being treated with a single drug or combination therapy $[7,8]$. The advent of PAH-specific therapies has improved the survival of $\mathrm{PAH}$ patients in comparison to historical registries. However, in spite of treatment, the mortality remains unacceptably high and survival for incident patients continues to be as low as $54.9 \% 3$ yrs after diagnosis $(95 \%$ CI 41.8-68.0) [9].

Although the structural changes that explain the "fixed $\mathrm{PH}^{\prime}$ of $\mathrm{PAH}$ patients have been described in recent decades [10-12] and major changes to the "classic" pathobiology of PAH have been described $[13,14]$, current PAH-specific drugs are predominantly vasodilators (although some anti-proliferative properties have been reported in cultured normal lung cells) [15]. Furthermore, the mechanisms underlying right ventricular failure (RVF) are incompletely understood [16, 17]. This review intends to put into perspective the pathobiological concepts of PAH and RVF, mainly derived from human studies, which reflect the progress that has been made in the understanding of this complex group of pulmonary vascular diseases.

\section{GENETIC INFLUENCES AND EPIGENETICS IN PAH}

The pathogenesis of PAH is based on one or more "hits", and genetic factors conferring a

\section{AFFILIATIONS}

${ }^{*}$ Dept of Medicine, Virginia

Commonwealth University,

Richmond, VA, and

"Dept of Pulmonary and Critical Care Medicine, Stanford University, Palo Alto, CA, USA.

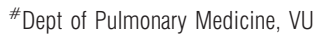
University Medical Center, Amsterdam, The Netherlands

\section{CORRESPONDENCE}

N.F. Voelkel

Victoria Johnson Center for

Obstructive Lung Disease Research

Virginia Commonwealth University

1220 East Broad Street

Richmond

VA 23298

USA

E-mail: nvoelkel@mcvh-vcu.edu

Received:

March 162012

Accepted after revision:

April 182012

First published online:

June 272012 
predisposition for the development or progression of severe PAH may be required (fig. 1) [18-20]. Mutations of the bone morphogenic type II receptor (BMPR2) gene, a member of the transforming growth factor (TGF)- $\beta$ superfamily, were first described in patients with familial/hereditary PAH (HPAH) [18]. Although BMPR2 mutations in HPAH have a high prevalence $(70 \%)$, limited numbers of patients with IPAH have mutations [19], and only $20 \%$ of the carriers ever develop PAH during their lifetime [19]. BMPR2 mutation carriers at the time of PAH diagnosis are younger $[20,21]$ and less likely to have a vasoreactive component [22]. A large number of mutations have been reported and the majority translate into a loss of function [23] or reduced BMPR2 expression [24]. It has been reported that the disease appears to be more severe when patients carry a truncating BMPR2 mutation [25]; however, this appears not to be the case in the French patients [21]. Mechanistic studies indicate that BMPR2 mutations are permissive but not necessary for the development of severe PAH. BMPR2 may be one of the "guardians" of lung vessel homeostasis, as gene knockout and silencing experiments have clearly demonstrated that both apoptosis and cell proliferation of pulmonary vascular smooth muscle and endothelial cells are controlled by BMPR2 [26]. Intact BMPR2 signalling may be necessary for the execution of a normal lung vascular wound-healing programme, preventing apoptosis-induced compensatory cell proliferation. BMPR2 loss makes cells more susceptible to apoptosis [27]; however, vascular cell apoptosis alone is insufficient for angioproliferation to occur. BMPR2 signalling appears to define the cellular identity during reparative responses [28]. BMP signalling is regulated at many different levels and each level could potentially contribute to abnormal BMPR2 function, without necessarily involving a mutation in the BMPR2 gene [26]. For example, mutations in the type I TGF- $\beta$ receptor, activin A receptor type-II like-1 [2931], have been observed in patients with severe PAH occurring in families with hereditary haemorrhagic telangiectasia. Moreover, although infrequent, mutations in the BMPR2 downstream mediators, the Smad proteins, have also been described in PAH patients [32]. In the aggregate the data indicate that BMP/TGF- $\beta$ signalling plays an important role in the maintenance of the normal lung arteriolar structure.

Epigenetic mechanisms influence gene expression via modifications of the chromatin, histones and regulatory microRNAs [33]. At present, there is no firm evidence that PAH has an epigenetic component [34]. Downregulation of BMPR2 expression has been explained by activation of a STAT3/miRNA-17-92 microRNA axis in normal human lung endothelial cells after interleukin (IL)-6 exposure [35]. Interestingly, mice overexpressing IL-6 develop severe PH [36] and, unlike other PH mice models, also develop angio-obliterative vascular remodelling and robust right ventricle (RV) hypertrophy [37]. Overexpression of miR-17 also increases proliferation of human pulmonary artery smooth muscle cells and inhibition with a specific miR-17 antagomir ameliorated $\mathrm{PH}$ in two experimental models [38]. Another microRNA, miRNA-204, has been found to be downregulated in pulmonary artery smooth muscle cells isolated from patients with PAH [39]. Upregulation of miR204 seems to induce an apoptosis-resistant phenotype in smooth muscle cells.

\section{THE PARADIGM SHIFT: FROM VASOCONSTRICTION TO CELL GROWTH}

Terms such as "cell phenotype switch", "apoptosis resistance" and "angiogenic niche" have introduced a new vocabulary which can be used to explain the pathobiology of PAH [40]. The early pioneers of $\mathrm{PH}$ research focused their attention on hypoxic vasoconstriction [41], and because the arachidonic acid-derived prostacyclin is a powerful inhibitor of hypoxic pulmonary vasoconstriction [42], it was thus intuitive to establish prostacyclin infusion as the first treatment for severe PAH [43]. Since then, rapid progress has been made. Our knowledge of the cellular and molecular components involved in the pathobiology of PAH has expanded and these new insights are likely to change our future approach to the treatment of PAH. We now regard the plexiform pulmonary vascular lesions as a product of an angioproliferative process leading to vascular occlusion (angio-obliteration) $[13,40]$ and we appreciate that these lesions are composed of a multitude of cell types, among them: actively dividing and phenotypically abnormal apoptosis-resistant endothelial cells with a monoclonal origin [44], progenitor cells [45] and immune cells [46-48]. Immunohistochemistry, using antibodies directed against cell surface epitopes and nuclear markers of cell activation, identifies different cell phenotypes with their expressed genes and proteins [40]. Hallmarks of cancer in angioproliferative PAH have been described, in particular, in angiogenesis [13], metabolic changes [49] and apoptosisresistant cells [50]. Based on the therapy refractoriness of $\mathrm{PAH}$, a hypothesis of "quasi-malignancy" has been proposed [40]: apoptosis may be the initiating event followed by the selection of proliferating apoptosis-resistant cells, some of which may be stem cells (fig. 1). PAH plexiform lesions also show decreased expression of the tumour-suppressor protein peroxisome proliferator activated receptor- $\gamma$ [51], while exhibiting increased expression of $\beta$-catenin, CXCR4 (a receptor involved in metastatic cell homing) and survivin, among others [40]. Survivin, an inhibitor of apoptosis, is expressed in many cancers, and cultured cells isolated from the lungs of PAH patients exhibit a markedly increased expression of survivin. Moreover, experimental gene therapy targeting this protein suppresses proliferation and ameliorates PAH in rats [52]. Another hallmark of cancer is the metabolic switch towards glycolysis (Warburg effect, perhaps as a defence against oxidative damage). Pulmonary arterial endothelial cells from IPAH patients cultured in vitro demonstrate reduced oxygen consumption, reduced mitochondrial respiration and increased glycolytic metabolism [49].

The "quasi-malignancy" disease model also accommodates the concept of a cancer stem cell/angiogenic niche [40]. Precursor cells can be transported into the pulmonary vascular adventitia via the vasa vasorum [53], stem cells can divide and migrate from a niche at the media-adventitia border zone [54] and pulmonary microvascular endothelial cell stem cells of small arteries [55] may proliferate to the point of lumen obliteration. It is presently unclear whether stem and precursor cells are friends or foes. For example, autologous endothelial progenitor cell transplantation therapy for $\mathrm{PAH}$ has reported positive results [56]. However, this early trial has been criticised [57] because the cells utilised for the clinical trial were not "true" progenitors. Conversely, anti c-Kit (a stem cell marker) 


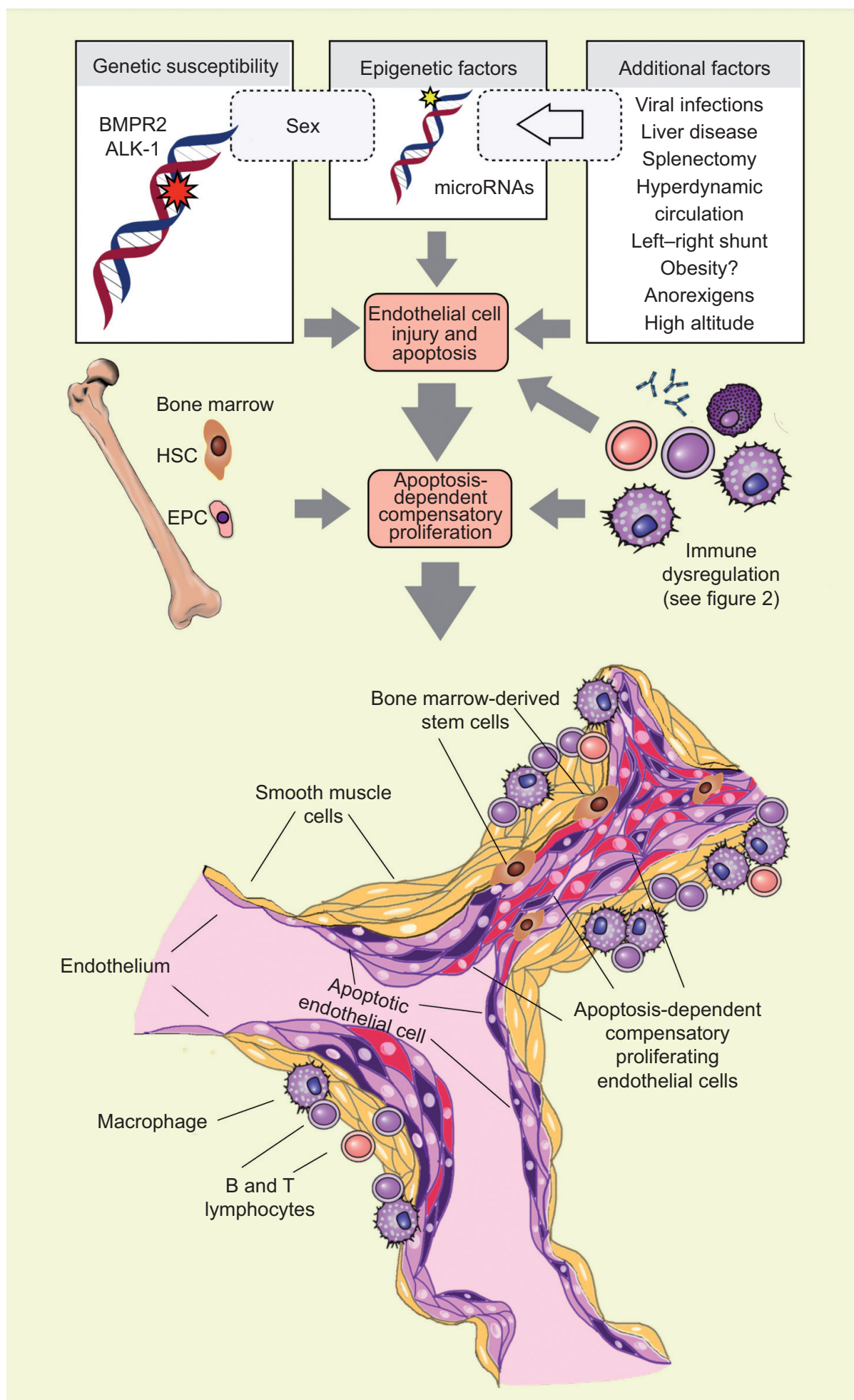

FIGURE 1. Hallmarks of severe angioproliferative pulmonary arterial hypertension. Genetic determinants, epigenetic factors and other conditions synergise and result in the injury and apoptosis of pulmonary arteriolar endothelial cells. Endothelial cell apoptosis triggers compensatory proliferation of phenotypically abnormal endothelial cells. Apoptosis may also be the initiating event, activating the bone marrow to release precursor and stem cells and eliciting a local immune response of the vascular wall. The end result is the complex vascular lesion, the plexiform lesion. These complex lesions obliterate the lumen of small arteries, predominantly localised to vessel bifurcations. The mature lesions are composed of endothelial cells (dark purple), smooth muscle cells (yellow), apoptotic cells (purple) and phenotypically altered apoptosis-resistant endothelial cells (red). These cells, together inflammatory cells, populate a microenvironment of exuberant cell growth. BMPR2: bone morphogenic type II receptor; ALK-1: activin A receptor type-Il like-1; HSC: hematopoietic stem cell; EPC: endothelial progenitor cell. 
treatment for $\mathrm{PAH}$ with the tyrosine kinase inhibitor imatinib mesylate, has demonstrated anecdotal positive results [58]. Stem cell-based gene therapy is currently being investigated in a clinical trial (Clinicaltrials.gov NCT00469027).

\section{GROWTH FACTORS AND RECEPTOR TYROSINE KINASES}

Many potent cell growth factors are overexpressed in IPAH vascular lesions, and it is probable that these growth factors and their receptor tyrosine kinases contribute to cell growth and vessel obliteration. Platelet derived growth factor (PDGF) has been extensively studied in PAH [59], and it has been shown that PDGF can induce the proliferation and migration of smooth muscle cells and fibroblasts. PDGF has been proposed as a key mediator in the progression of several fibroproliferative disorders. It was postulated that PDGF receptor blockers could reverse $\mathrm{PAH}$, based on the case report of a patient with endstage IPAH treated with imatinib mesylate. Subsequently, a clinical safety trial evaluating imatinib mesylate as a treatment of advanced forms of PAH was performed [60]. The data showed a significant decrease in pulmonary vascular resistance (PVR) and a moderate increase in cardiac output, but no significant change in pulmonary artery pressures, leading to the conclusion that imatinib mesylate may have a limited role in the treatment of IPAH patients. Other tyrosine kinase inhibitors for PAH are being studied [61, 62]. It is important that the tyrosine kinase inhibitors imatinib, sorafenib and nilotinib were shown in animal studies to be acute pulmonary vasodilators [63]. However, the vasodilator effect in clinical studies of PAH was not prominent. This is an example that identifying highly specific molecular targets in $\mathrm{PAH}$ animal models that do not reproduce the salient features of human $\mathrm{PAH}$ may be misleading and the drug effect may be lost in translation [37, 64]. Paradoxically, dasatinib, a multi-tyrosine kinase inhibitor, has been associated with the development of PAH $[65,66]$.

\section{INFLAMMATION AND IMMUNE RESPONSE}

The association of autoimmune disorders with PAH and the presence of antinuclear and anti-phospholipid antibodies in the serum of patients with IPAH has been appreciated for many years [67]. There is more evidence that lymphoid neogenesis occurs in IPAH; macrophages, mast cells, T- and B- lymphocytes, plasma cells and anti-endothelial cell antibodies are present in and around the complex pulmonary vascular lesions in IPAH patients $[13,48]$. Serum levels of IL-1 and IL-6 are high in IPAH patients [68], and serum IL-6 levels negatively predict patient survival [69]. However, whether inflammation and aberrant immune responses in IPAH are cause or consequence remains unknown. It is probable that PH occurs when an inflammatory pulmonary arteriolar injury is not resolved by (normally) protective, innate anti-inflammatory mechanisms. Regulatory T-cells (Tregs) not only control other T-cells but also regulate monocytes, macrophages, dendritic cells, natural killer cells and $B$ cells [70], and recent evidence suggests that decreased Treg cell number or function may favour the development of $\mathrm{PH}$ [71]. For example, conditions associated with PAH, such as HIV, systemic sclerosis, systemic lupus erythematosus, Hashimoto's thyroiditis, Sjögren's syndrome and the anti-phospholipid syndrome are characterised by abnormal CD4+ T-cell number and function [72-77]. At the experimental level, athymic rats lacking T-cells develop pronounced $\mathrm{PH}$ after vascular injury with a vascular endothelial growth factor receptor blocker. The lungs in these animals are populated by infiltrating macrophages, mast cells and B cells, similar to human PAH lesions [71, 78]. Most importantly, $\mathrm{PH}$ is prevented by immune reconstitution of Tregs prior to the induction of vascular injury [71]. Altogether, it is a possibility that aberrant Treg cell function in the face of vascular injury can result in heightened innate and adaptive immune responses that could initiate and/or propagate the development of $\mathrm{PH}$ (fig. 2) [79]. Despite the increasing evidence suggesting a role for immune deregulation in $\mathrm{PAH}$, there is only limited anecdotal evidence suggesting that $\mathrm{PH}$ associated with connective tissue disorders, such as systemic lupus erthyematosis and systemic sclerosis, or viral infections, such as human herpes virus-8, can respond to gluococorticoids or targeted B cell depletion [80, 81]. SANCHEZ et al. [82] and JAIS et al. [83] reported on the treatment of patients with mixed connective tissue disease-, or systemic lupus erythematosus-associated $\mathrm{PH}$, where corticosteroid and cyclophosphamide have been used as firstline drugs. The effectiveness of $\mathrm{B}$ cell depletion is currently being put to the test with an National Institute of Health trial examining the effectiveness of rituximab, a chimeric monoclonal antibody against the protein CD20 and primarily expressed by Bcells, for systemic sclerosis-associated $\mathrm{PH}$ (Clinicaltrials.gov NCT01086540).

It is becoming apparent that circulating factors can probably amplify lung vascular injury, attract immune cells and/or repair cells which respond to a variety of chemotactic stimuli, perhaps suggesting a systemic disease component contributing to the development or progression of PAH. In the modern era of PAH treatment, where standard vasodilation therapies have failed to reverse or stop the progression of $\mathrm{PAH}$, novel targets such as discrete immune pathways hold promise. However, new drugs and clinical trials will require the assessment of which patients may respond to anti-inflammatory treatment strategies.

\section{THE RIGHT VENTRICLE-LUNG CIRCULATION AXIS}

Patients with severe PAH die from RVF. The interactions between the remodelled lung circulation and the RV are only partially understood [16]. RVF is commonly seen as a consequence of chronic RV pressure overload and a developing imbalance between RV oxygen demand and supply, sometimes culminating into RV ischaemia. Indeed, increased $P$ pa increases $\mathrm{RV}$ wall tension and oxygen consumption, and at the same time is associated with compromised coronary blood flow. However, and remarkably, patients with Eisenmenger's syndrome physiology generate a degree of RV afterload similar to that of patients with IPAH, but have a much better survival and only develop overt RVF at a late stage of their disease [84]. Similarly, some patients, at the time of PAH diagnosis, present with signs and symptoms of RVF while other patients with the same degree of RV afterload present in New York Heart Association (NYHA) functional class I with no signs of RVF. Based on mechanistic animal studies, it has been proposed that, in addition to pressure overload, other factors, perhaps products of the sick lung circulation, contribute to RV dysfunction (fig. 3) $[85,86]$. Similar to left heart failure, it has been postulated that RVF is characterised by an abnormal energy metabolism [87]. Positron emission tomography studies have demonstrated increased accumulation of the radiopharmaceutical glucose analogue ${ }^{18} \mathrm{~F}$-2-deoxy-2-fluoro-D-glucose $\left({ }^{18} \mathrm{FDG}\right)$ in the RV of 

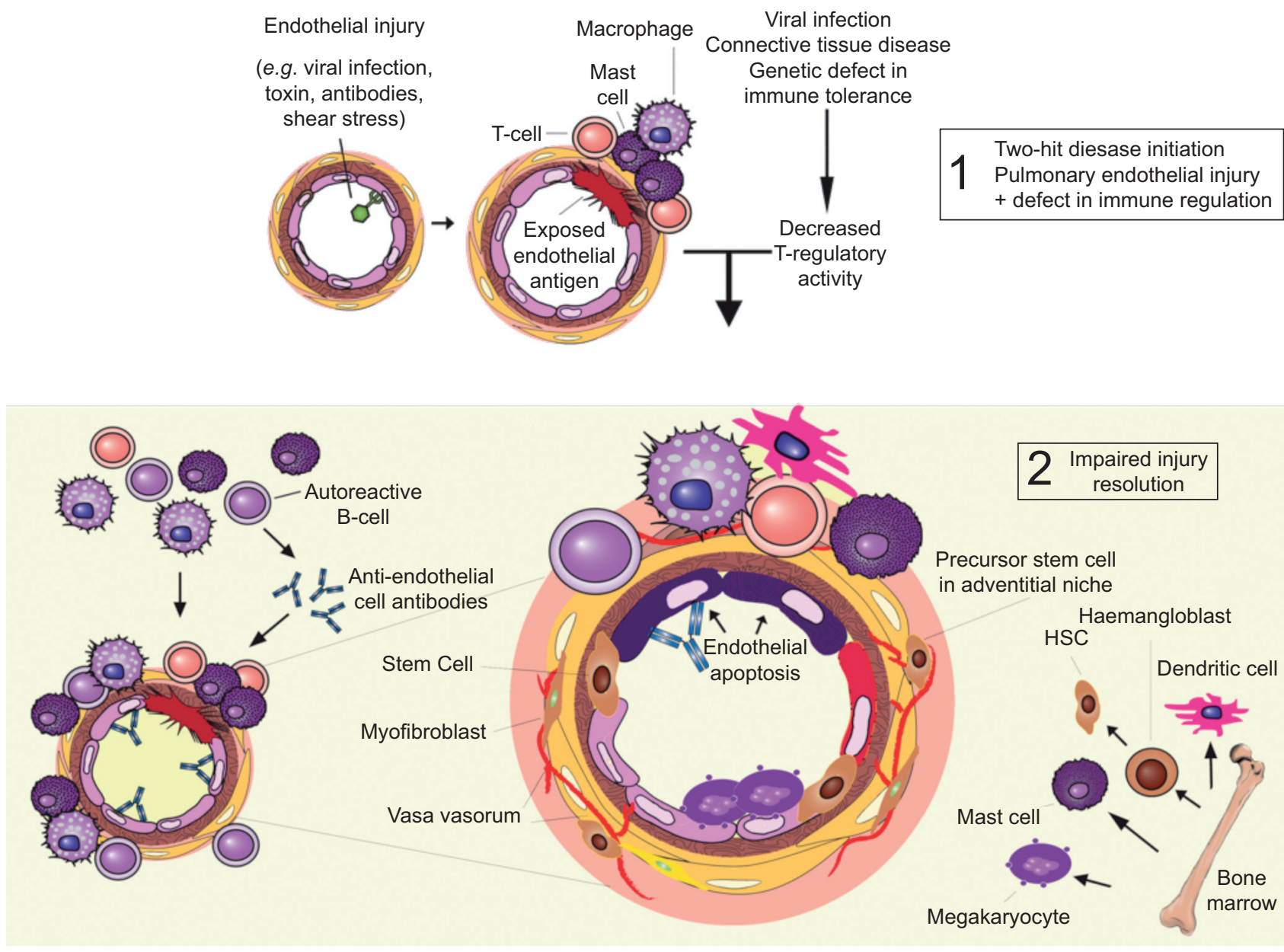

FIGURE 2. Participation of the immune system in pulmonary vascular remodelling. The initial arteriolar endothelial cell injury can be due to mechanical stress, toxins or antibodies. The "two-hit" hypothesis considers that defective immune regulation, such as in HIV/AIDS and scleroderma, participates in the lumen-obliterating cell growth [1] and in the impaired injury resolution [2]. The disease model depicted here reflects the complexity of multicellular interactions within and around the vascular wall and the active role of the bone marrow and inflammatory and immune cells in the pathobiology of pulmonary arterial hypertension. The multi-growth factor-producing mast cell was the first of several immune cells to be identified in the perivascular space of pulmonary arterioles in lungs from patients with severe pulmonary hypertension. It may populate these vessels because of hyperplasia (in situ expansion of mast cell number) or after being recruited from the bone marrow. An impaired activity of regulatory T-cells may facilitate the angio-obliteration. HSC: hematopoietic stem cell.

PAH patients, in comparison to normal subjects [88, 89]. However, increased, ${ }^{18}$ FDG uptake does not seem to correlate with disease severity. A recent study showed no difference in ${ }^{18}$ FDG uptake between NYHA class II and class III PAH patients, even when there was a clear-cut difference in cardiac output [90]. Moreover, this study found no correlation between RV ${ }^{18} \mathrm{FDG}$ uptake and RV mechanical efficiency. It is important to remember that ${ }^{18}$ FDG uptake studies have limitations and that the physiological interpretation is not straightforward. Tracer uptake can be influenced by multiple factors [91]. Moreover, ${ }^{18}$ FDG avidity represents the total amount of ${ }^{18}$ FDG present in the tissue at the time of image acquisition [92], which is not necessarily equal to the total amount of ${ }^{18} \mathrm{FDG}$ absorption by the cell. Instead, the scan also captures the ${ }^{18}$ FDG present in the blood and intercellular spaces. Perhaps the most prominent limitation of ${ }^{18}$ FDG study interpretation is explained by its chemical structure. ${ }^{18}$ FDG lacks the functional hydroxyl group that is required for the enzyme phosphoglucose isomerase (the second enzymatic step of glycolysis) to function properly [93]. Briefly, ${ }^{18}$ FDG cannot be further metabolised inside the cells. Thus, ${ }^{18}$ FDG uptake studies are too crude to identify a "metabolic switch" in the failing RV. Whereas, experimental studies have demonstrated that RVF exhibits increased expression of glycolysis-related genes [94] and increased enzymatic glycolysis rates [95], a complete characterisation of RV "metabolic remodelling" in human PAH-associated RVF is still lacking.

Noninvasive imaging technologies, in particular echocardiography and cardiac magnetic resonance imaging (CMRI), are now providing a more complete assessment of the structural and functional changes of the failing and non-failing RV in the setting of chronic PAH. Whereas changes in longitudinal shortening (tricuspid annulus plane systolic excursion) have been the standard measure to evaluate RV dysfunction [96], other changes in RV morphology have been shown to correlate with survival. For example, a large RV volume and impaired left ventricular filling, assessed by CMRI, are strong independent predictors of mortality and treatment failure [97]. It has 


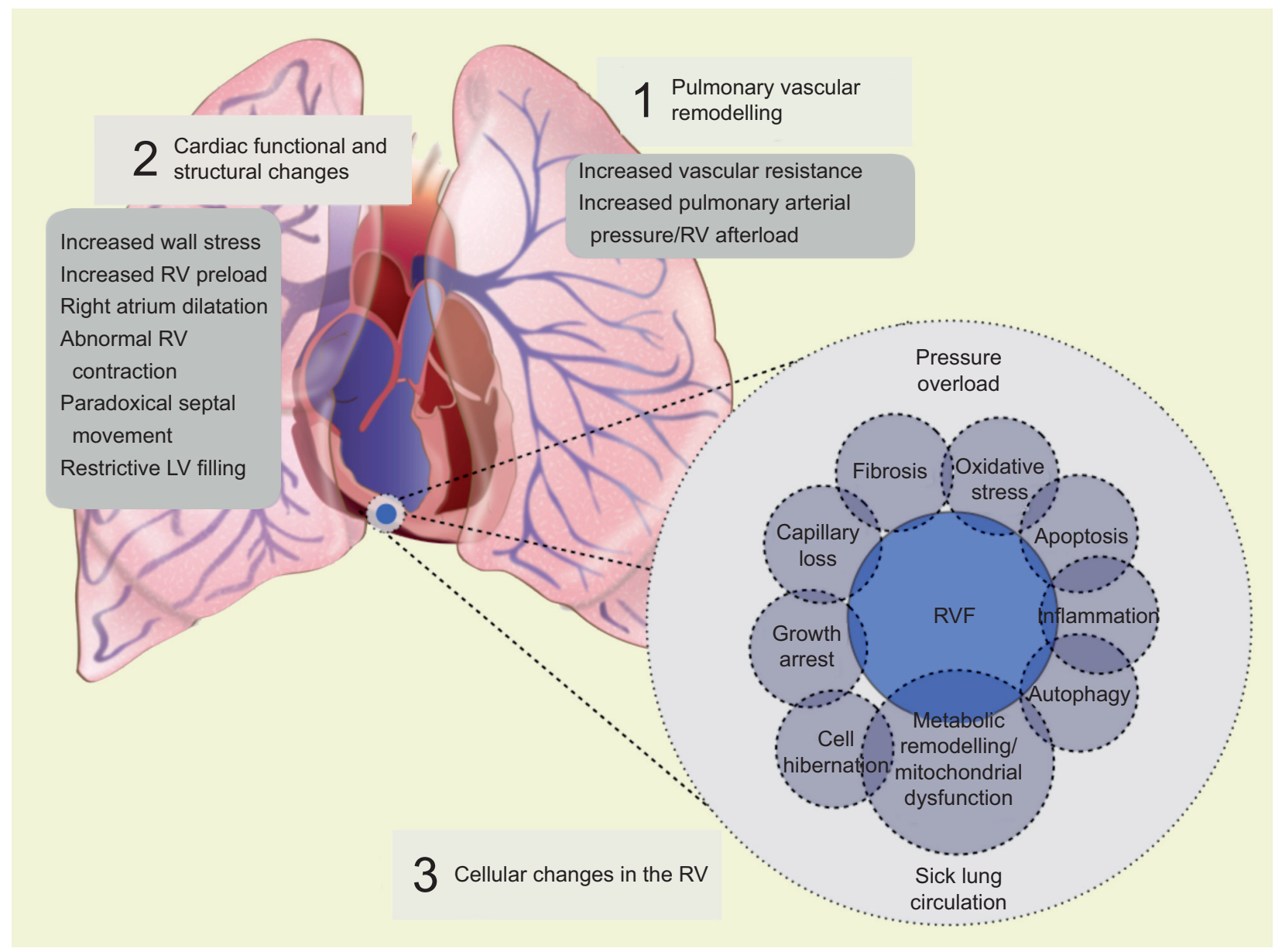

FIGURE 3. The sick lung circulation-right heart failure axis. Increased pulmonary vascular resistance generates a significant afterload for the right ventricle resulting in right ventricular hypertrophy. The structural and functional changes during the development of right ventricular failure can be characterised clinically [2]. Right ventricular dysfunction is probably associated with multiple cellular changes [3], such as oxidative stress, apoptosis, inflammation, fibrosis and metabolic remodelling. These factors also contribute to right ventricle (RV) dysfunction and failure. The cellular changes are either the result of chronic RV pressure overload or the effect of circulating factors released from the sick lung circulation. RVF: right ventricle failure; LV: left ventricle.

also been reported that decreased RV longitudinal shortening and free-wall motion at the time of diagnosis do not significantly change over time, whereas RV transverse shortening continues to decline over time in non-survivor $\mathrm{PAH}$ patients [98]. RV transverse shortening could be particularly valuable for the monitoring of treatment success or failure, as we move forward with clinical trials for RV-targeted therapies. Measurement of RV free wall longitudinal deformation (strain) and the rate of deformation by speckle-tracking strain echocardiography have been shown to identify patients with greater severity of RV dysfunction [99]. Most importantly, changes in RV strain correlate significantly with functional class and can predict mortality. Finally, the prognostic importance of RVF in patients with PAH has recently been revisited. VAN DE VEERDONK et al. [100] reported that although elevated PVR (in treated PAH patients) is associated with higher mortality, the $\mathrm{RV}$ ejection fraction (measured by CMRI) is the strongest predictor of survival, even after a response to vasodilator therapy has been established. Other noninvasive imaging tools to evaluate RV dysfunction in PAH patients have been described previously [101-104].

\section{CHALLENGES OF PAH TREATMENT}

The future of the medical management of PAH faces multiple obstacles. 1) In spite of improved screening tools, PAH is not discovered during its early stage and treatment is often delayed. Data from the REVEAL registry indicate that the lag-time from the onset of symptoms to right heart catheterisation has not changed compared with the data published based on the first National Institute of Health registry [105]. 2) Although improvements in survival have been demonstrated in clinical trials, the overall patient survival in the "modern era" remains low and the survival of "incident" PAH patients appears to be similar to that of the idiopathic $\mathrm{PH}$ patients enrolled in the first National Institute of Health registry [8]. Indeed, the concept of vasodilator drug treatment for PAH has become controversial in the last decade (for reasons discussed previously). In one meta-analysis, MACCHIA and co-workers $[106,107]$ called PAH "a clinical condition looking for new drugs and research methodology" and stated "whether current therapies of PAH improve long-term survival has never been demonstrated in a randomised clinical trial". However, the meta-analysis of MACCHIA and co-workers [106, 107] was 


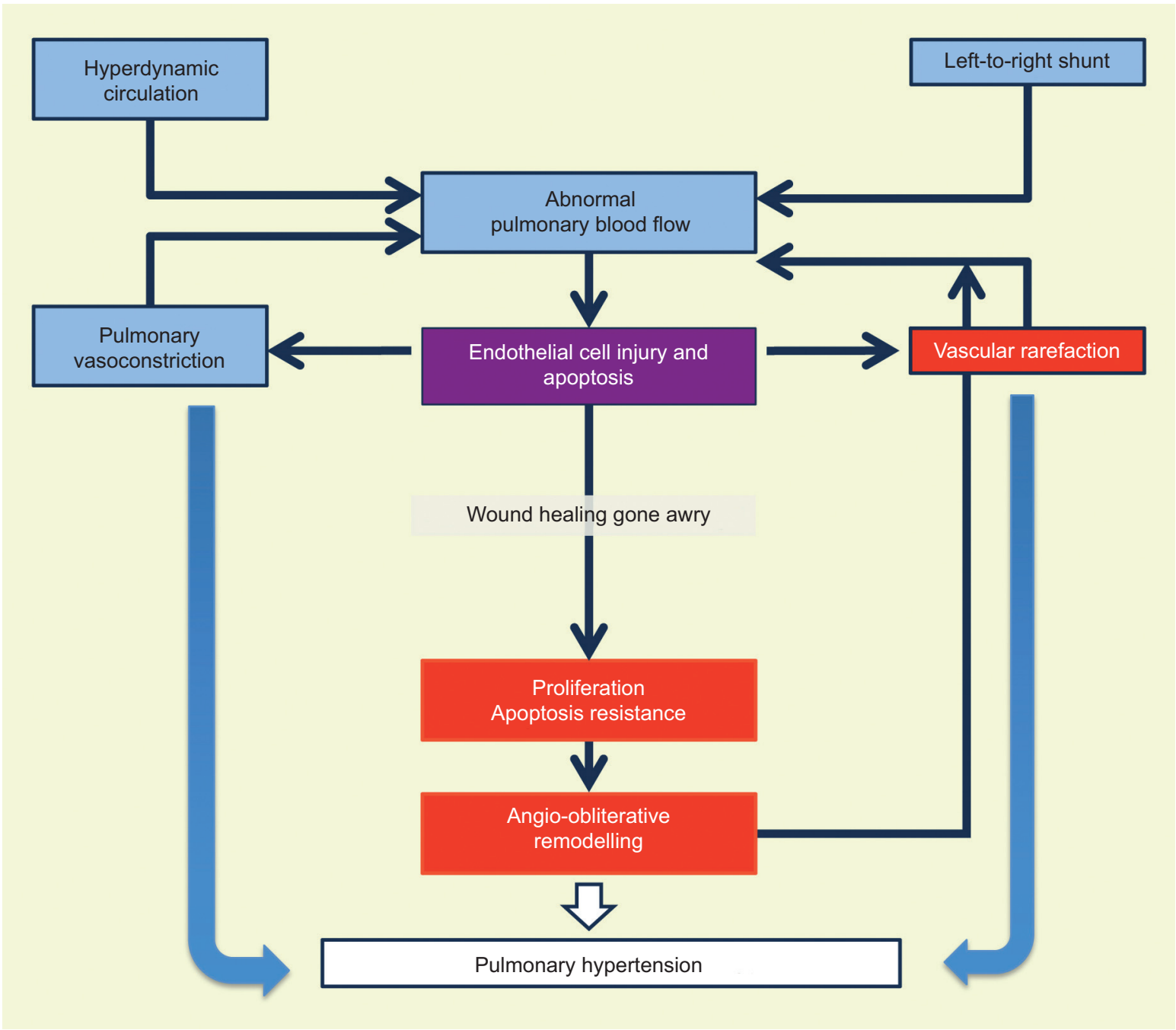

FIGURE 4. Integration of haemodynamic and cellular events that characterise the cardiopulmonary disease of severe pulmonary arterial hypertension (PAH). The pathophysiology of $\mathrm{PAH}$, which operates via mechanical concepts, is complemented with concepts of cell injury and repair and interactions of complex multicellular systems. The model is built on the principle of abnormal pulmonary blood flow. Regional blood flow abnormalities underlie the pulmonary vascular remodelling, which in turn causes further alterations of the regional blood flow, perpetuating a cycle of cell death and cell proliferation. Vascular rarefaction occurs in the form of pruning of the small lung vessels, and in the right ventricle in the form of myocardial capillary rarefaction.

criticised due to the fact that many of the studies assessed were underpowered to determine mortality [108]. A later metaanalysis by GALIĖ et al. [108], which included 23 randomised controlled trials performed exclusively in $\mathrm{PAH}$ patients, reported that a reduction of $43 \%$ in overall mortality was observed in the groups randomised to active treatments when compared with those randomised to placebo. However, the average duration of the trials assessed was limited (14.3 weeks) and, with the exception of the first epoprostenol trial [43], none of the trials defined survival as a primary end-point. 3) Future therapeutic strategies face one particular critical paradox: while the remodelled lung circulation in $\mathrm{PAH}$ is characterised by angiogenesis, apoptosis resistance and cell proliferation, the failing RV suffers from ischaemia [109], capillary rarefaction and cardiomyocyte apoptosis [86], conditions that could be worsened by pharmacotherapy targeting pulmonary vascular remodelling. One example could be the tyrosine kinase inhibitors, which are known to be cardiotoxic [110].

\section{CONCLUSIONS}

$\mathrm{PAH}$ is increasingly recognised not as one disease but as a group of diseases where genetic susceptibility renders patients vulnerable to a chronic pulmonary microangiopathy. It appears that increased afterload of the RV is insufficient to explain right heart failure, as it is best illustrated by the better prognosis and longer survival of patients with Eisenmenger's physiology. Further explorations of the molecular mechanisms of cell reprogramming in $\mathrm{PAH}$, in both the lung vessels and the heart, should lead to a better understanding of this group of diseases. The classical pathophysiology of $\mathrm{PAH}$, which operates with the mechanical concepts of pressure, flow, shear stress, RV wall stress and impedance, should be complemented with the new pathobiological concepts of cell injury and repair and interactions of complex multicellular systems (fig. 4). Precursor and stem cells derived from the bone marrow and resident lung vascular stem cells should also be considered as active players in the process of pulmonary vascular wound healing "gone awry". 
Many questions remain. Is there an early vasoreactive disease phase in PAH? Can the inflammatory disease component, discussed above, be treated in most patients? Do patients with reactive PAH (treatable with calcium-channel blockers) and PAH patients with NYHA class I, which does not progress after several years, represent pathogenetically unique subgroups? The former, a vasospastic variant, the latter, a variant characterised by a robust afterload and stress resilient right ventricle. Can prevention of RV dysfunction prolong life?

As new treatment strategies appear on the horizon, clinical trials should consider investigating the mechanisms of treatment success or treatment failure by comparing treatment responders and non-responders, as is currently the novel approach developed for cancer treatment trials [111, 112]. PAH should be viewed as a cardiopulmonary system disease, which is based on the paradox of apoptosis, apoptosis-resistant growth of phenotypically abnormal cells and angiogenesis in the lungs, and apoptosis and capillary loss in the heart. Thus, new therapeutic strategies should consider that drugs originally designed to tackle angiogenesis in PAH lungs could potentially have a profound, negative impact on the failing RV. Integrating new pathobiological concepts will become critical as we design new medical therapies in order to change the prognosis of patients with this fatal group of diseases.

\section{STATEMENT OF INTEREST}

None declared.

\section{REFERENCES}

1 Galie N, Hoeper M, Humbert M, et al. Guidelines for the diagnosis and treatment of pulmonary hypertension. Eur Respir J 2009; 34: 1219-1263.

2 Frost AE, Badesch DB, Barst RJ, et al. The changing picture of patients with pulmonary arterial hypertension in the United States: how REVEAL differs from historic and non-US Contemporary Registries. Chest 2011; 139: 128-137.

3 Humbert M, Sitbon O, Chaouat A, et al. Pulmonary arterial hypertension in France: results from a national registry. Am J Respir Crit Care Med 2006; 173: 1023-1030.

4 Peacock AJ, Murphy NF, McMurray JJV, et al. An epidemiological study of pulmonary arterial hypertension. Eur Respir J 2007; 30: 104-109.

5 Escribano-Subias P, Blanco I, López-Meseguer M, et al. Survival in pulmonary hypertension in Spain insights from the Spanish registry. Eur Respir J 2012; 40: 596-603.

6 Humbert M, Khaltaev N, Bousquet J, et al. Pulmonary hypertension: from an orphan disease to a public health problem. Chest 2007; 132: 365-367.

7 Benza RL, Miller DP, Gomberg-Maitland M, et al. Predicting survival in pulmonary arterial hypertension: insights from the Registry to Evaluate Early and Long-Term Pulmonary Arterial Hypertension Disease Management (REVEAL). Circulation 2010; 122: $164-172$.

8 Humbert M, Sitbon O, Chaouat A, et al. Survival in patients with idiopathic, familial, and anorexigen-associated pulmonary arterial hypertension in the modern management era. Circulation 2010; 122: 156-163.

9 Humbert M, Sitbon O, Yaici A, et al. Survival in incident and prevalent cohorts of patients with pulmonary arterial hypertension. Eur Respir J 2010; 36: 549-555.

10 Wagenvoort CA. Pathology of lung-tissue and lung vessels in valvular heart-disease. B Eur Physiopath Res 1977; 13: P9-P10.
11 Rabinovitch M. Molecular pathogenesis of pulmonary arterial hypertension. J Clin Invest 2008; 118: 2372-2379.

12 Archer S, Rich S. Primary pulmonary hypertension: a vascular biology and translational research "work in progress". Circulation 2000; 102: 2781-2791.

13 Tuder RM, Groves B, Badesch DB, et al. Exuberant endothelial cell growth and elements of inflammation are present in plexiform lesions of pulmonary hypertension. Am J Pathol 1994; 144: 275-285.

14 Schermuly RT, Ghofrani HA, Wilkins MR, et al. Mechanisms of disease: pulmonary arterial hypertension. Nat Rev Cardiol 2011; 8: 443-455.

15 Humbert M, Sitbon O, Simonneau G. Treatment of pulmonary arterial hypertension. N Engl J Med 2004; 351: 1425-1436.

16 Voelkel NF, Quaife RA, Leinwand LA, et al. Right ventricular function and failure: report of a National Heart, Lung, and Blood Institute working group on cellular and molecular mechanisms of right heart failure. Circulation 2006; 114: 1883-1891.

17 Bogaard HJ, Abe K, Vonk Noordegraaf A, et al. The right ventricle under pressure: cellular and molecular mechanisms of right-heart failure in pulmonary hypertension. Chest 2009; 135: 794-804.

18 Newman JH, Wheeler L, Lane KB, et al. Mutation in the gene for bone morphogenetic protein receptor II as a cause of primary pulmonary hypertension in a large kindred. N Engl J Med 2001; 345: 319-324.

19 Machado RD, Eickelberg O, Elliott CG, et al. Genetics and genomics of pulmonary arterial hypertension. J Am Coll Cardiol 2009; 54: Suppl. 1, S32-S42.

20 Pfarr N, Szamalek-Hoegel J, Fischer C, et al. Hemodynamic and clinical onset in patients with hereditary pulmonary arterial hypertension and BMPR2 mutations. Respir Res 2011; 12: 99.

21 Girerd B, Montani D, Eyries M, et al. Absence of influence of gender and BMPR2 mutation type on clinical phenotypes of pulmonary arterial hypertension. Respir Res 2010; 11: 73.

22 Elliott CG, Glissmeyer EW, Havlena GT, et al. Relationship of BMPR2 mutations to vasoreactivity in pulmonary arterial hypertension. Circulation 2006; 113: 2509-2515.

23 Machado RD, Pauciulo MW, Thomson JR, et al. BMPR2 haploinsufficiency as the inherited molecular mechanism for primary pulmonary hypertension. Am J Hum Genet 2001; 68: 92-102.

24 Atkinson C, Stewart S, Upton PD, et al. Primary pulmonary hypertension is associated with reduced pulmonary vascular expression of type II bone morphogenetic protein receptor. Circulation 2002; 105: 1672-1678.

25 Austin ED, Phillips JA, Cogan JD, et al. Truncating and missense BMPR2 mutations differentially affect the severity of heritable pulmonary arterial hypertension. Respir Res 2009; 10: 87.

26 Morrell NW. Pulmonary hypertension due to BMPR2 mutation: a new paradigm for tissue remodeling? Proc Am Thorac Soc 2006; 3: 680-686.

27 Teichert-Kuliszewska K, Kutryk MJB, Kuliszewski MA, et al. Bone morphogenetic protein receptor-2 signaling promotes pulmonary arterial endothelial cell survival: implications for loss-of-function mutations in the pathogenesis of pulmonary hypertension. Circ Res 2006; 98: 209-217.

28 Trompouki E, Bowman TV, Lawton LN, et al. Lineage regulators direct BMP and Wnt pathways to cell-specific programs during differentiation and regeneration. Cell 2011; 147: 577-589.

29 Trembath RC, Thomson JR, Machado RD, et al. Clinical and molecular genetic features of pulmonary hypertension in patients with hereditary hemorrhagic telangiectasia. $N$ Engl J Med 2001; 345: 325-334.

30 Girerd B, Montani D, Coulet F, et al. Clinical outcomes of pulmonary arterial hypertension in patients carrying an 
ACVRL1 (ALK1) mutation. Am J Respir Crit Care Med 2010; 181: 851-861.

31 Sztrymf B, Coulet F, Girerd B, et al. Clinical outcomes of pulmonary arterial hypertension in carriers of BMPR2 mutation. Am J Respir Crit Care Med 2008; 177: 1377-1383.

32 Nasim MT, Ogo T, Ahmed M, et al. Molecular genetic characterization of SMAD signaling molecules in pulmonary arterial hypertension. Hum Mutat 2011; 32: 1385-1389.

33 Holliday R. Epigenetics: a historical overview. Epigenetics 2006; 1: 76-80.

34 Kim GH, Ryan JJ, Marsboom G, et al. Epigenetic mechanisms of pulmonary hypertension. Pulm Circ 2011; 1: 347-356.

35 Brock M, Trenkmann M, Gay RE, et al. Interleukin-6 modulates the expression of the bone morphogenic protein receptor type II through a novel STAT3-microRNA cluster 17/92 pathway. Circ Res 2009; 104: 1184-1191.

36 Steiner MK, Syrkina OL, Kolliputi N, et al. Interleukin-6 overexpression induces pulmonary hypertension. Circ Res 2009; 104: 236-244.

37 Gomez-Arroyo JG, Saleem SJ, Mizuno S, et al. A brief overview of mouse models of pulmonary arterial hypertension: problems and prospects. Am J Physiol Lung Cell Mol Physiol 2012; 302: L977-L991.

38 Pullamsetti SS, Doebele C, Fischer A, et al. Inhibition of microRNA-17 improves lung and heart function in experimental pulmonary hypertension. Am J Respir Crit Care Med 2012; 185 409-419.

39 Courboulin A, Paulin R, Giguère NJ, et al. Role for miR-204 in human pulmonary arterial hypertension. J Exp Med 2011; 208: 535-548.

40 Rai PR, Cool CD, King JAC, et al. The cancer paradigm of severe pulmonary arterial hypertension. Am J Respir Crit Care Med 2008; 178: 558-564.

41 Weir EK, Will DH, Alexander AF, et al. Vascular hypertrophy in cattle susceptible to hypoxic pulmonary hypertension. J Appl Physiol 1979; 46: 517-521.

42 Voelkel NF, Gerber JG, McMurtry IF, et al. Release of vasodilator prostaglandin, PGI2, from isolated rat lung during vasoconstriction. Circ Res 1981; 48: 207-213.

43 Barst RJ, Rubin LJ, Long WA, et al. A comparison of continuous intravenous epoprostenol (prostacyclin) with conventional therapy for primary pulmonary hypertension. The Primary Pulmonary Hypertension Study Group. N Engl J Med 1996; 334: 296-302.

44 Lee SD, Shroyer KR, Markham NE, et al. Monoclonal endothelial cell proliferation is present in primary but not secondary pulmonary hypertension. J Clin Invest 1998; 101: 927-934.

45 Montani D, Perros F, Gambaryan N, et al. C-Kit-Positive cells accumulate in remodeled vessels of idiopathic pulmonary arterial hypertension. Am J Respir Crit Care Med 2011; 184: 116-123.

46 Cool CD, Stewart JS, Werahera $\mathrm{P}$, et al. Three-dimensional reconstruction of pulmonary arteries in plexiform pulmonary hypertension using cell-specific markers. Evidence for a dynamic and heterogeneous process of pulmonary endothelial cell growth. Am J Pathol 1999; 155: 411-419.

47 Perros F, Dorfmuller P, Souza R, et al. Dendritic cell recruitment in lesions of human and experimental pulmonary hypertension. Eur Respir J 2007; 29: 462-468.

48 Perros F, Dorfmuller P, Montani D, et al. Pulmonary lymphoid neogenesis in idiopathic pulmonary arterial hypertension. Am J Respir Crit Care Med 2012; 185: 311-321.

$49 \mathrm{Xu} \mathrm{W}$, Koeck $\mathrm{T}$, Lara $\mathrm{AR}$, et al. Alterations of cellular bioenergetics in pulmonary artery endothelial cells. Proc Natl Acad Sci USA 2007; 104: 1342-1347.

50 Sakao S, Taraseviciene-Stewart L, Cool CD, et al. VEGF-R blockade causes endothelial cell apoptosis, expansion of surviving
CD34+ precursor cells and transdifferentiation to smooth musclelike and neuronal-like cells. FASEB J 2007; 21: 3640-3652.

51 Ameshima S, Golpon H, Cool CD, et al. Peroxisome proliferatoractivated receptor gamma (PPAR $\gamma$ ) expression is decreased in pulmonary hypertension and affects endothelial cell growth. Circ Res 2003; 92: 1162-1169.

52 McMurtry MS, Archer SL, Altieri DC, et al. Gene therapy targeting survivin selectively induces pulmonary vascular apoptosis and reverses pulmonary arterial hypertension. J Clin Invest 2005; 115: 1479-1491.

53 Yeager ME, Frid MG, Stenmark KR. Progenitor cells in pulmonary vascular remodeling. Pulm Circ 2011; 1: 3-16.

54 Ergun S, Tilki D, Klein D. Vascular wall as a reservoir for different types of stem and progenitor cells. Antioxid Redox Signal 2011; 15: 981-995.

55 Alvarez DF, Huang L, King JA, et al. Lung microvascular endothelium is enriched with progenitor cells that exhibit vasculogenic capacity. Am J Physiol Lung Cell Mol Physiol 2008; 294: L419-L430.

56 Wang X-X, Zhang F-R, Shang Y-P, et al. Transplantation of autologous endothelial progenitor cells may be beneficial in patients with idiopathic pulmonary arterial hypertension: a pilot randomized controlled trial. J Am Coll Cardiol 2007; 49: 1566-1571.

57 Toshner M, Morrell NW. Endothelial progenitor cells in pulmonary hypertension - dawn of cell-based therapy? Int Clin Pract Suppl 2010; 165: 7-12.

58 Ghofrani HA, Seeger W, Grimminger F. Imatinib for the treatment of pulmonary arterial hypertension. N Engl J Med 2005; 353: 1412-1413.

59 Perros F, Montani D, Dorfmuller P, et al. Platelet-derived growth factor expression and function in idiopathic pulmonary arterial hypertension. Am J Respir Crit Care Med 2008; 178: 81-88.

60 Ghofrani HA, Morrell NW, Hoeper MM, et al. Imatinib in pulmonary arterial hypertension patients with inadequate response to established therapy. Am J Respir Crit Care Med 2010; 182: 1171-1177.

61 O'Callaghan DS, Savale L, Montani D, et al. Treatment of pulmonary arterial hypertension with targeted therapies. Nat Rev Cardiol 2011; 8: 526-538.

62 Gomberg-Maitland M, Maitland ML, Barst RJ, et al. A dosing/ cross-development study of the multikinase inhibitor sorafenib in patients with pulmonary arterial hypertension. Clin Pharmacol Ther 2010; 87: 303-310.

63 Abe K, Toba M, Alzoubi A, et al. Tyrosine kinase inhibitors are potent acute pulmonary vasodilators in rats. Am J Respir Cell Mol Biol 2011; 45: 804-808.

64 Gomez-Arroyo JG, Farkas L, Alhussaini AA, et al. The monocrotaline model of pulmonary hypertension in perspective. Am J Physiol Lung Mol Cell Physiol 2012; 302: L363-L369.

65 Hennigs JK, Keller G, Baumann HJ, et al. Multi tyrosine kinase inhibitor dasatinib as novel cause of severe pre-capillary pulmonary hypertension? BMC Pulm Med. 2011; 11: 30.

66 Montani D, Bergot E, Günther S, et al. Pulmonary arterial hypertension in patients treated by dasatinib. Circulation 2012; 125: 2128-2137.

67 Nicolls MR, Taraseviciene-Stewart L, Rai PR, et al. Autoimmunity and pulmonary hypertension: a perspective. Eur Respir J 2005; 26: 1110-1118.

68 Humbert M, Monti G, Brenot F, et al. Increased interleukin-1 and interleukin-6 serum concentrations in severe primary pulmonary hypertension. Am J Respir Crit Care Med 1995; 151: 1628-1631.

69 Soon E, Holmes AM, Treacy CM, et al. Elevated levels of inflammatory cytokines predict survival in idiopathic and familial pulmonary arterial hypertension. Circulation 2010; 122: 920-927. 
70 Sakaguchi S. Naturally arising CD4+ regulatory $\mathrm{T}$ cells for immunologic self-tolerance and negative control of immune responses. Annu Rev Immunol 2004; 22: 531-562.

71 Tamosiuniene R, Tian W, Dhillon G, et al. Regulatory T cells limit vascular endothelial injury and prevent pulmonary hypertension. Circ Res 2011; 109: 867-879.

72 Speich R, Jenni R, Opravil M, et al. Primary pulmonary hypertension in HIV infection. Chest 1991; 100: 1268-1271.

73 Radstake TR, van Bon L, Broen J, et al. Increased frequency and compromised function of $\mathrm{T}$ regulatory cells in systemic sclerosis (SSc) is related to a diminished CD69 and TGF $\beta$ expression. PLoS One 2009; 4: e5981.

74 Bonelli M, Savitskaya A, Steiner CW, et al. Phenotypic and functional analysis of CD4+ CD25- Foxp3+ T cells in patients with systemic lupus erythematosus. J Immunol 2009; 182: 1689-1695.

75 Covas MI, Esquerda A, Garcia-Rico A, et al. Peripheral blood Tlymphocyte subsets in autoimmune thyroid disease. I Investig Allergol Clin Immunol 1992; 2: 131-135.

76 Mandl T, Bredberg A, Jacobsson LT, et al. CD4+ T-lymphocytopenia - a frequent finding in anti-SSA antibody seropositive patients with primary Sjogren's syndrome. J Rheumatol 2004; 31: 726-728.

77 Papo T, Piette JC, Legac E, et al. T lymphocyte subsets in primary antiphospholipid syndrome. J Rheumatol 1994; 21: 2242-2245.

78 Taraseviciene-Stewart L, Nicolls MR, Kraskauskas D, et al. Absence of $\mathrm{T}$ cells confers increased pulmonary arterial hypertension and vascular remodeling. Am J Respir Crit Care Med 2007; 175: 1280-1289.

79 Kim JM, Rasmussen JP, Rudensky AY. Regulatory T cells prevent catastrophic autoimmunity throughout the lifespan of mice. Nat Immunol 2007; 8: 191-197.

80 Kato M, Kataoka H, Odani $\mathrm{T}$, et al. The short-term role of corticosteroid therapy for pulmonary arterial hypertension associated with connective tissue diseases: report of five cases and a literature review. Lupus 2011; 20: 1047-1056.

81 Hennigan S, Channick RN, Silverman GJ. Rituximab treatment of pulmonary arterial hypertension associated with systemic lupus erythematosus: a case report. Lupus 2008; 17: 754-756.

82 Sanchez O, Sitbon O, Jais X, et al. Immunosuppressive therapy in connective tissue diseases-associated pulmonary arterial hypertension. Chest 2006; 130: 182-189.

83 Jais X, Launay D, Yaici A, et al. Immunosuppressive therapy in lupus- and mixed connective tissue disease-associated pulmonary arterial hypertension: a retrospective analysis of twentythree cases. Arthritis Rheum 2008; 58: 521-531.

84 Hopkins WE, Ochoa LL, Richardson GW, et al. Comparison of the hemodynamics and survival of adults with severe primary pulmonary hypertension or Eisenmenger syndrome. J Heart Lung Transplant 1996; 15: 100-105.

85 Erzurum S, Rounds SI, Stevens T, et al. Strategic plan for lung vascular research: an NHLBI-ORDR workshop report. Am J Respir Crit Care Med 2010; 182: 1554-1562.

86 Bogaard HJ, Natarajan R, Henderson SC, et al. Chronic pulmonary artery pressure elevation is insufficient to explain right heart failure. Circulation 2009; 120: 1951-1960.

87 Tuder RM, Davis LA, Graham BB. Targeting energetic metabolism: a new frontier in the pathogenesis and treatment of pulmonary hypertension. Am J Respir Crit Care Med 2012; 185: 260-266.

88 Can MM, Kaymaz C, Tanboga IH, et al. Increased right ventricular glucose metabolism in patients with pulmonary arterial hypertension. Clin Nucl Med 2011; 36: 743-748.

89 Oikawa M, Kagaya Y, Otani H, et al. Increased [18F] fluorodeoxyglucose accumulation in right ventricular free wall in patients with pulmonary hypertension and the effect of epoprostenol. J Am Coll Cardiol 2005; 45: 1849-1855.
90 Wong YY, Ruiter G, Lubberink M, et al. Right ventricular failure in idiopathic pulmonary arterial hypertension is associated with inefficient myocardial oxygen utilization. Circ Heart Fail 2011; 4: 700-706.

91 Hariharan R, Bray M, Ganim R, et al. Fundamental limitations of $\left[{ }^{18} \mathrm{~F}\right]$ 2-deoxy-2-fluoro-D-glucose for assessing myocardial glucose uptake. Circulation 1995; 91: 2435-2444.

92 Schwaiger M, Hicks R. The clinical role of metabolic imaging of the heart by positron emission tomography. J Nucl Med 1991; 32: 565-578.

93 Topper YJ. On the mechanism of action of phosphoglucose isomerase and phosphomannose isomerase. J Biol Chem 1957; 225: 419-425.

94 Drake JI, Bogaard HJ, Mizuno S, et al. Molecular signature of a right heart failure program in chronic severe pulmonary hypertension. Am J Respir Cell Mol Biol 2011; 45: 1239-1247.

95 Piao L, Fang Y-H, Cadete VJJ, et al. The inhibition of pyruvate dehydrogenase kinase improves impaired cardiac function and electrical remodeling in two models of right ventricular hypertrophy: resuscitating the hibernating right ventricle. J Mol Med 2010; 88: 47-60.

96 Forfia PR, Fisher MR, Mathai SC, et al. Tricuspid annular displacement predicts survival in pulmonary hypertension. Am J Respir Crit Care Med 2006; 174: 1034-1041.

97 van Wolferen SA, Marcus JT, Boonstra A, et al. Prognostic value of right ventricular mass, volume, and function in idiopathic pulmonary arterial hypertension. Eur Heart J 2007; 28: 1250-1257.

98 Mauritz G-J, Kind T, Marcus JT, et al. Progressive changes in right ventricular geometric shortening and long-term survival in pulmonary arterial hypertension. Chest 2012; 141: 935-943.

99 Sachdev A, Villarraga HR, Frantz RP, et al. Right ventricular strain for prediction of survival in patients with pulmonary arterial hypertension. Chest 2011; 139: 1299-1309.

100 van de Veerdonk MC, Kind T, Marcus JT, et al. Progressive right ventricular dysfunction in patients with pulmonary arterial hypertension responding to therapy. J Am Coll Cardiol 2011; 58: 2511-2519.

101 Benza R, Biederman R, Murali S, et al. Role of cardiac magnetic resonance imaging in the management of patients with pulmonary arterial hypertension. J Am Coll Cardiol 2008; 52: $1683-1692$.

102 Vonk-Noordegraaf A, Galiè N. The role of the right ventricle in pulmonary arterial hypertension. Eur Respir Rev 2011; 20: 243-253.

103 Gupta H, Ghimire G, Naeije R. The value of tools to assess pulmonary arterial hypertension. Eur Respir Rev 2011; 20: 222-235.

104 Valsangiacomo Buechel ER, Mertens LL. Imaging the right heart: the use of integrated multimodality imaging. Eur Heart J 2012; 33: 949-960.

105 Brown LM, Chen H, Halpern S, et al. Delay in recognition of pulmonary arterial hypertension: factors identified from the REVEAL Registry. Chest 2011; 140: 19-26.

106 Macchia A, Marchioli R, Marfisi R, et al. A meta-analysis of trials of pulmonary hypertension: a clinical condition looking for drugs and research methodology. Am Heart J 2007; 153: 1037-1047.

107 Macchia A, Marchioli R, Tognoni G, et al. Systematic review of trials using vasodilators in pulmonary arterial hypertension: why a new approach is needed. Am Heart J 2010; 159: 245-257.

108 Galiè N, Manes A, Negro L, et al. A meta-analysis of randomized controlled trials in pulmonary arterial hypertension. Eur Heart $J$ 2009; 30: 394-403.

109 Gómez A, Bialostozky D, Zajarias A, et al. Right ventricular ischemia in patients with primary pulmonary hypertension. JAAC 200, 38: 1137-1142. 
110 Force T, Krause DS, Van Etten RA. Molecular mechanisms of cardiotoxicity of tyrosine kinase inhibition. Nat Rev Cancer 2007; 7: $332-344$.

111 Fiebig $\mathrm{H}-\mathrm{H}$, Schüler J, Bausch $\mathrm{N}$, et al. Gene signatures developed from patient tumor explants grown in nude mice to predict tumor response to 11 cytotoxic drugs. Cancer Genomics Proteomics 2007; 4: 197-209.

112 Ferriss JS, Kim Y, Duska L, et al. Multi-gene expression predictors of single drug responses to adjuvant chemotherapy in ovarian carcinoma: predicting platinum resistance. PLoS One 2012; 7: e30550. 